\title{
The Correlation between the Ratio of Visceral Fat Area to Subcutaneous Fat Area on Computed Tomography and Lipid Accumulation Product as Indexes of Cardiovascular Risk
}

\author{
SoHee Kwon', A Lum Han ${ }^{2, *}$ \\ ${ }^{1}$ Professional Graduate School of Oriental Medicine, Wonkwang University, Iksan; ${ }^{2}$ Department of Family Medicine, Wonkwang University Hospital, Iksan, Korea
}

Background: Visceral obesity and cardiovascular disease are closely related. Research on relevant indexes of cardiovascular disease is particularly important. One of these indexes is lipid accumulation product (LAP). However, the relationship between LAP and the ratio of visceral fat area to subcutaneous fat area (V/S ratio) remains unclear.

Methods: Individuals who visited the university hospital health promotion center and underwent abdominal computed tomography (CT) were included in the study. We analyzed the V/S ratio obtained using CT with cardiovascular factors and indexes. Standardized coefficients were used to obtain uniform units of all independent variables, and the relationship between LAP and V/S ratio was determined using multiple logistic regression analysis.

Results: A positive correlation between the V/S ratio and LAP was observed even after adjustment for age, smoking history, alcohol drinking history, and exercise $(P<0.001)$. The highest quartile of LAP was independently associated with abdominal obesity (odds ratio [OR], 1.160; 95\% confidence interval [Cl], 1.093-1.232) and visceral fat $\geq 100 \mathrm{~cm}^{2}(\mathrm{OR}, 1.018 ; 95 \% \mathrm{Cl}, 1.010-1.026)$, but not with hypertension or diabetes.

Conclusion: $\mathrm{LAP}$ is closely related to the $\mathrm{V} / \mathrm{S}$ ratio and can be used to predict the condition of visceral fat tissue.

\author{
Received April 2, 2019 \\ Reviewed April 26, 2019 \\ Accepted September 9, 2019 \\ *Corresponding author \\ A Lum Han \\ iD \\ https://orcid.org/0000-0002-6509-7953 \\ Department of Family Medicine, \\ Wonkwang University Hospital, \\ 895 Muwang-ro, lksan 54538, Korea \\ Tel: +82-63-859-1301 \\ Fax: +82-63-859-1306 \\ E-mail: qibosarang@naver.com
}

Key words: Lipid accumulation product, Visceral fat, Subcutaneous fat

\section{INTRODUCTION}

Obesity is ultimately linked to cardiovascular disease (CVD), and there are many ways to define obesity. ${ }^{1}$ Obesity, sometimes defined as the amount of visceral fat, is associated with CVD. ${ }^{1,2}$ Waist circumference (WC) is an indicator of obesity that reflects abdominal visceral fat and is easy to measure. ${ }^{1-3}$ On the other hand, computed tomography (CT) is expensive and carries the disadvantage of risk, including radiation exposure. Nevertheless, the measurements of visceral and subcutaneous fat by $\mathrm{CT}$ or magnetic reso- nance imaging more accurately reflect the amount of visceral fat and various metabolic diseases and cardiovascular risk. ${ }^{4,5}$ Although body fat affects metabolic syndrome, several studies have shown that patients with high abdominal visceral to subcutaneous fat ratios are the most vulnerable to diabetes and CVDs. ${ }^{4,5}$ Compared with Caucasian individuals, Asian individuals are more prone to diabetes and CVDs because they have more abdominal visceral fat than subcutaneous fat. ${ }^{6}$ Various indexes have been developed for fat tissue, CVD, and metabolic disease. ${ }^{1,2}$

Indeed, the relative distribution of abdominal fat may be more

Copyright (c) 2019 Korean Society for the Study of Obesity

@ This is an Open Access article distributed under the terms of the Creative Commons Attribution Non-Commercial License (http://creativecommons.org/licenses/by-nc/4.0/) which permits unrestricted non-commercial use, distribution, and reproduction in any medium, provided the original work is properly cited. 
important than visceral and subcutaneous fat area itself because the ratio of visceral fat area to subcutaneous fat area ( $\mathrm{V} / \mathrm{S}$ ratio) is more strongly related to the risk of CVD than visceral fat area. ${ }^{7}$ Moreover, the subcutaneous fat area has a beneficial role against metabolic diseases. ${ }^{7}$ Established in the Caucasian population, the visceral adiposity index is a reliable indicator of visceral fat function associated with cardio-metabolic risk. ${ }^{8}$ Clinical anthropometric indicators, such as lipid accumulation product (LAP), are described in the literature as sensitive and specific indicators for discriminating visceral fat compared to the classic parameters, such as WC and body mass index (BMI). ${ }^{8} \mathrm{LAP}$ is an alternative measure of excessive lipid accumulation and is calculated as a combination of WC and fasting plasma triglyceride (TG) ${ }^{8,9}$ It was created to simultaneously reflect the anatomical and physiological changes associated with lipid overaccumulation in adults. ${ }^{9}$ LAP reflects the risk of CVD relatively well, and according to international studies, it is also associated with insulin resistance, metabolic syndrome, and diabetes. ${ }^{10}$

Lipid ratios, which are risk factors for CVD, showed a close correlation with insulin resistance and metabolic syndrome. ${ }^{11,12}$ Previous observations revealed that ratios, in terms of their ability to predict cardiovascular events over a follow-up period of 5 years, and that take into account concentrations of atherogenic and antiatherogenic lipoproteins, are superior to measurements of concentrations of either atherogenic or anti-atherogenic fractions alone. ${ }^{13}$ These lipid ratios include total cholesterol:high-density lipoprotein cholesterol (HDL-C), non-HDL-C:HDL-C, and low-density lipoprotein cholesterol (LDL-C):HDL-C. ${ }^{13}$ Based on the aforementioned previous studies, we evaluated the relationship between the $\mathrm{V} / \mathrm{S}$ ratio, obtained through abdominal CT, and various indexes related to CVD and metabolic disease. The various indexes included lipid ratio and LAP, which are related to CVD.

\section{METHODS}

\section{Study subjects}

Data was collected from urban-dwelling adult men and women ages 20 to 75 years who visited a university hospital health promotion center and underwent a medical examination and abdominal CT. Those with incomplete medical histories or medication records, those with chronic diseases other than hypertension or diabetes, and those who had previously received cancer treatment or were diagnosed with cancer were excluded. A total of 530 subjects were included in the final analysis. The charts of examinees who have already undergone medical examinations were reviewed. Thus, a request for exemption of informed consent was submitted for this study and approved by Institutional Review Board (IRB). The study protocol was also approved by the IRB of Wonkwang University Hospital in Seoul, Korea (IRB No. WKUH 2019-02-016-002).

\section{Measures}

Questionnaire, anthropometric measurements, and blood

\section{pressure}

The subjects completed a self-administered questionnaire and were interviewed by physicians. Anthropometric measurements were performed by trained nurses. Height and weight were measured using automatic measurement devices (Inbody330; Biospace Co., Ltd., Seoul, Korea), and the BMI was obtained by dividing the weight by the square of the height $\left(\mathrm{kg} / \mathrm{m}^{2}\right)$. WC was measured by placing a tape measure in the midpoint horizontally between the lowest point of the costal margin and the highest point of the pelvic iliac crest with the patient in an upright position, following the World Health Organization recommendations. Blood pressure was measured on the right arm after 10 minutes of rest using an automatic blood pressure measurement device (BP-8800C; Colin Electronics Co., Ltd., Aichi, Japan). The blood pressure measurement was repeated if the systolic blood pressure (SBP) was $>140 \mathrm{mmHg}$ or the diastolic blood pressure (DBP) was $>90 \mathrm{mmHg}$. Average SBP and DBP were recorded.

\section{Blood tests}

The subjects fasted for at least 12 hours, and a blood sample was collected and analyzed under fasting conditions. Hemoglobin, glycosylated hemoglobin, fasting plasma glucose, total cholesterol, TG, HDL-C, and LDL-C levels were measured using the ADVIA 1650 analyzer (Bayer Diagnostics, Tarrytown, NY, USA).

\section{Defining the LAP}

LAP is defined and calculated as follows :

$\mathrm{LAP}$ for men $=(\mathrm{WC}[\mathrm{cm}]-65) \times(\mathrm{TG}$ concentration $[\mathrm{mmol} / \mathrm{L}])$ $\mathrm{LAP}$ for women $=(\mathrm{WC}[\mathrm{cm}]-58) \times(\mathrm{TG}$ concentration $[\mathrm{mmol} / \mathrm{L}])$ 


\section{Abdominal fat area}

A fat area in the abdomen was defined as an area with -150 to -50 Hounsfield units on CT. Subcutaneous fat in the abdomen was defined as the fat located between the skin and the rectus abdominis muscle, obliquus abdominis muscle, and erector spinae muscle at the level of the navel. Visceral fat was defined as the fat between the rectus abdominis muscle, obliquus abdominis muscle, quadratus lumborum muscle, psoas muscle, and lumbar vertebrae at the same level. Three horizontal, 10-mm-thick abdominal CT sections obtained at the L4-5 level were selected to calculate the average visceral fat area and subcutaneous fat area. The $\mathrm{V} / \mathrm{S}$ ratio was determined by dividing the visceral fat area by the subcutaneous fat area measured by CT.

\section{Statistical analysis}

We used SPSS version 11.5 (SPSS Inc., Chicago, IL, USA) for statistical analyses. Statistical significance was indicated by a $P$-value $<0.05$. We used the Shapiro-Wilk test to test normality. The association between the $\mathrm{V} / \mathrm{S}$ ratio and independent variables (lipid ratio, LAP) was determined using a multiple regression analysis. Then, the related factors were corrected, and the relationship between the LAP and V/S ratio was determined using multiple logistic regression analysis.

\section{RESULTS}

\section{General characteristics of the study subjects}

Of the 530 subjects, $60.2 \%$ were male, $39.8 \%$ were female, and the average age was 54 years. The subjects engaged in aerobic exercise an average of $1.0 \pm 1.8$ times per week and consumed alcohol an average of $1.4 \pm 1.9$ times per week. Of the total sample, 356 individuals were current smokers (68.2\%). With respect to cardiovascular risk indicators, the average BMI was $24.6 \pm 3.3 \mathrm{~kg} / \mathrm{m}^{2}$, the average WC was $84.3 \pm 9.1 \mathrm{~cm}$, and the average blood pressure was within the prehypertensive level (SBP, $121.8 \pm 13.5 \mathrm{mmHg}$; DBP, $74.0 \pm 10.1 \mathrm{mmHg}$ ). The mean LAP was 2,725.5 $\pm 2,619.1$, and V/S ratio was $0.5 \pm 0.5$. There were 121 patients $(23.2 \%)$ with hypertension and 51 with diabetes (9.8\%). The mean values of other variables are shown in Table 1.
Table 1. General characteristics of the participants

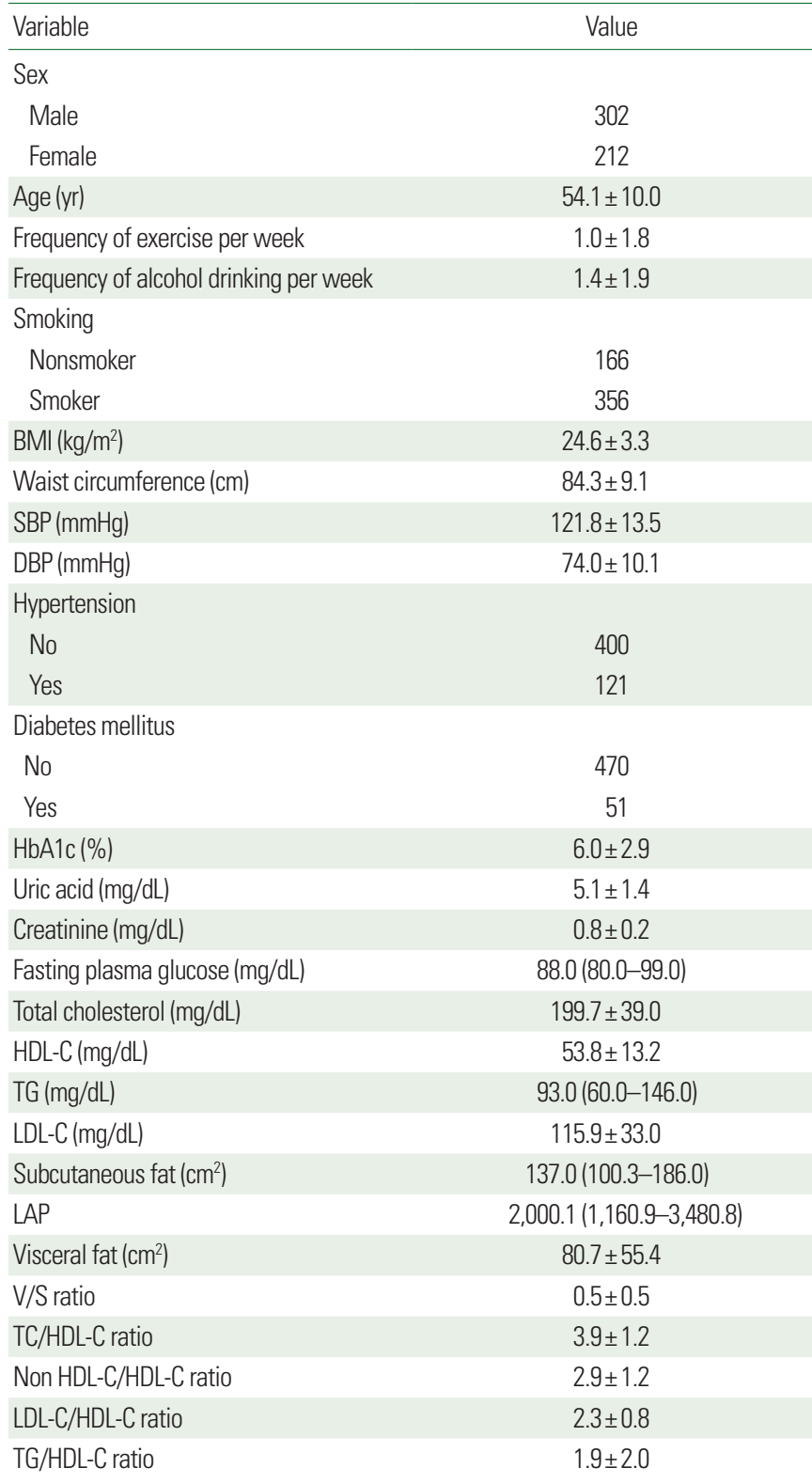

Values are presented as number, mean \pm standard deviation, or median (01-03). BMI, body mass index; SBP, systolic blood pressure; DBP, diastolic blood pressure; $\mathrm{HbA1c}$, glycosylated hemoglobin; HDL-C, high-density lipoprotein cholesterol; TG, triglyceride; LDL-C, low-density lipoprotein cholesterol; LAP, lipid accumulation product; $\mathrm{V} / \mathrm{S}$ ratio, the ratio of visceral fat area to subcutaneous fat area; TC, total cholesterol; 0 , quartile.

\section{Correlation between LAP and V/S ratio}

We performed a simple linear regression analysis with the independent variables shown in Table 1 and the dependent variable $\mathrm{V} / \mathrm{S}$ ratio. Then, multiple regression analysis was conducted using adjusted variables that were significant in simple linear regression analysis. The results showed the following: the higher the subcutaneous fat, 
Table 2. Correlation between V/S ratio and cardiovascular risk factors

\begin{tabular}{lrrrr}
\hline \multirow{2}{*}{ Variable } & \multicolumn{4}{c}{ V/S ratio } \\
\cline { 2 - 5 } & $\mathrm{B}^{*}$ & \multicolumn{1}{c}{$\beta^{\dagger}$} & \multicolumn{1}{c}{$P^{\ddagger}$} & \multicolumn{1}{c}{$95 \% \mathrm{Cl}$} \\
\hline Age (yr) & -0.015 & -0.040 & 0.340 & -0.046 to 0.016 \\
Smoking behavior & -0.820 & -0.107 & 0.015 & -1.478 to -0.163 \\
Alcohol intake/wk & -0.021 & -0.011 & 0.796 & -0.176 to 0.135 \\
Exercise/wk & -0.060 & -0.032 & 0.418 & -0.207 to 0.086 \\
BMI (kg/m²) & -0.344 & -0.316 & $<0.001$ & -0.477 to -0.210 \\
WC (cm) & 0.273 & 0.713 & $<0.001$ & 0.217 to 0.329 \\
HbA1c (\%) & 0.019 & 0.016 & 0.696 & -0.076 to 0.113 \\
Fasting plasma glucose $(\mathrm{mg} / \mathrm{dL})$ & -0.009 & -0.068 & 0.111 & -0.020 to 0.002 \\
Subcutaneous fat $\left(\mathrm{cm}^{2}\right)$ & -0.026 & -0.515 & $<0.001$ & -0.032 to -0.021 \\
Visceral fat (cm ${ }^{2}$ ) & -0.002 & -0.032 & 0.584 & -0.009 to 0.005 \\
LAP & 0.0005 & 0.348 & $<0.001$ & 0.0002 to 0.001 \\
TG/HDL-C ratio & -0.221 & -0.262 & $<0.001$ & -0.337 to -0.104 \\
\hline
\end{tabular}

${ }^{*}$ Beta coefficient; ${ }^{\dagger}$ Standardized beta coefficient; ${ }^{\ddagger} P$-values were calculated using multiple regression analysis adjusted for age, smoking behavior, frequency of alcohol intake/week, and frequency of exercise per week.

$\mathrm{V} / \mathrm{S}$ ratio, the ratio of visceral fat area to subcutaneous fat area; $\mathrm{Cl}$, confidence interval; $\mathrm{BMI}$, body mass index; WC, waist circumference; HbA1c, glycosylated hemoglobin; LAP, lipid accumulation product; TG, triglyceride; HDL-C, high-density lipoprotein cholesterol.

the lower the $\mathrm{V} / \mathrm{S}$ ratio $(\beta,-0.026, P<0.001)$; the higher LAP, the higher the $\mathrm{V} / \mathrm{S}$ ratio $(\beta, 0.0005, P<0.001)$; and the lower the TG/ $\mathrm{HDL}-\mathrm{C}$ ratio, the lower the $\mathrm{V} / \mathrm{S}$ ratio $(\beta,-0.221, P<0.001)$.

Since the units of independent variables were different, standardized coefficients were used to obtain uniform units of all independent variables. We used standardized coefficients to determine which variables greatly affected the dependent variables. The results showed that $\mathrm{V} / \mathrm{S}$ ratio decreases as the subcutaneous fat rises $(\beta,-0.515, P<0.001), \mathrm{V} / \mathrm{S}$ ratio increases as LAP increases $(\beta$, $0.348, P<0.001)$, and $\mathrm{V} / \mathrm{S}$ ratio decreases as the TG/HDL ratio increases $(\beta,-0.262, P<0.001)$. When the units of independent variables were standardized, there was a tendency to affect the $\mathrm{V} / \mathrm{S}$ ratio in the following order: subcutaneous fat, LAP, and TG/HDL ratio (Table 2).

\section{Relationship between clinical cardiovascular characteristics and $\mathrm{V} / \mathrm{S}$ ratio}

We categorized the $\mathrm{V} / \mathrm{S}$ ratio by quartiles and analyzed the relationship between the variables and $\mathrm{V} / \mathrm{S}$ ratio while adjusting for general characteristics. Compared to that in individuals with WC $<90 \mathrm{~cm}$, the odds of obtaining a $\mathrm{V} / \mathrm{S}$ ratio $>0.48$ (interquartile range, 0.53$)$ is 0.206 times higher in individuals with $\mathrm{WC} \geq 90 \mathrm{~cm}$ $(P<0.001)$. Furthermore, the odds of obtaining a $\mathrm{V} / \mathrm{S}$ ratio $>0.48$
Table 3. Risk of V/S ratio (>0.48) according to other cardiovascular risk factors

\begin{tabular}{lcr}
\hline Variable & OR $(95 \% \mathrm{Cl})$ & \multicolumn{1}{c}{$P^{*}$} \\
\hline $\mathrm{BMI} \geq 25 \mathrm{~kg} / \mathrm{m}^{2}$ & $1.157(0.664-2.016)$ & 0.606 \\
$\mathrm{WC} \geq 90 \mathrm{~cm}$ & $0.206(0.092-0.462)$ & $<0.001$ \\
Visceral fat $\geq 100 \mathrm{~cm}^{2}$ & $16.540(7.430-36.823)$ & $<0.001$ \\
Hypertension & - & \\
No & $1.215(0.638-2.311)$ & 0.554 \\
Yes & - & \\
Diabetes mellitus & & \\
No & $0.559(0.247-1.268)$ & 0.164 \\
Yes & $1.043(1.017-1.069)$ & 0.001 \\
Age & $3.064(1.719-5.464)$ & $<0.001$ \\
Smoking behavior & $1.381(1.175-1.624)$ & $<0.001$ \\
Frequency of alcohol drinking/wk & $1.055(0.932-1.194)$ & 0.399 \\
Frequency of exercise/wk & \\
\hline
\end{tabular}

* $P$-values were calculated using multiple logistic regression adjusted for age, smoking behavior, frequency of alcohol intake/week, and frequency of exercise per week.

$\mathrm{V} / \mathrm{S}$ ratio, the ratio of visceral fat area to subcutaneous fat area; $\mathrm{OR}$, odds ratio; $\mathrm{Cl}$, confidence interval; BMI, body mass index; WC, waist circumference.

was 16.54 times higher in individuals with visceral fat $\geq 100 \mathrm{~cm}^{2}$ compared to that in individuals with visceral fat $<100 \mathrm{~cm}^{2}(P<$ $0.001)$. Moreover, the results showed that, while the WC is closely related to the $\mathrm{V} / \mathrm{S}$ ratio, the presence or absence of hypertension and diabetes is not significantly associated with the $\mathrm{V} / \mathrm{S}$ ratio $(P<$ 0.001) (Table 3).

\section{Relationship between clinical cardiovascular characteristics and LAP}

We categorized the LAP by quartiles and analyzed the relationship between the variables and LAP while adjusting for the general characteristics. Compared to that in individuals with $\mathrm{WC}<90 \mathrm{~cm}$, the odds of obtaining a LAP $>2,000.05$ (median) is 1.160 times higher in individuals with WC $\geq 90 \mathrm{~cm}$ WC $(P<0.001)$. Furthermore, the odds of obtaining a LAP $>2,000.05$ was 1.018 times higher in individuals with visceral fat $\geq 100 \mathrm{~cm}^{2}$ compared to that in individuals with visceral fat $<100 \mathrm{~cm}^{2}(P<0.001)$. Moreover, the results showed that, while the WC is closely related to LAP, the presence or absence of hypertension and diabetes is not significantly associated with LAP $(P<0.001)$ (Table 4$)$.

\section{DISCUSSION}

This study focused on LAP among CVD-related indexes and 
Table 4. Risk of LAP ( > 2,000.05) according to other cardiovascular risk factors

\begin{tabular}{lcc}
\hline Variable & OR (95\% Cl) & $P^{*}$ \\
\hline $\mathrm{BMI} \geq 25 \mathrm{~kg} / \mathrm{m}^{2}$ & $1.081(0.951-1.230)$ & 0.233 \\
$\mathrm{WC} \geq 90 \mathrm{~cm}$ & $1.160(1.093-1.232)$ & $<0.001$ \\
Visceral fat $\geq 100 \mathrm{~cm}^{2}$ & $1.018(1.010-1.026)$ & $<0.001$ \\
Hypertension & - & \\
$\quad$ No & $1.494(0.804-2.777)$ & 0.204 \\
$\quad$ Yes & - & \\
Diabetes mellitus & $1.132(0.498-2.574)$ & 0.767 \\
$\quad$ No & $0.965(0.937-0.993)$ & 0.016 \\
Yes & $0.772(0.436-1.365)$ & 0.373 \\
Age & $1.003(0.874-1.151)$ & 0.968 \\
Smoking behavior & $1.031(0.906-1.174)$ & 0.641 \\
Frequency of alcohol drinking/wk & & \\
Frequency of exercise/wk &
\end{tabular}

${ }^{*}$-values were calculated using multiple logistic regression adjusted for age, smoking behavior, frequency of alcohol intake per week, and frequency of exercise per week. $\mathrm{LAP}$, lipid accumulation product; $\mathrm{OR}$, odds ratio; $\mathrm{Cl}$, confidence interval; $\mathrm{BMI}$, body mass index; $\mathrm{WC}$, waist circumference.

evaluated its association with the $\mathrm{V} / \mathrm{S}$ ratio. There have been studies that investigated the relationship between LAP and insulin resistance and CVD, ${ }^{9,10}$ but no domestic studies have confirmed a correlation between $\mathrm{LAP}$ and $\mathrm{V} / \mathrm{S}$ ratio. In this study, the lipid ratio had no particular association with the V/S ratio, but LAP was correlated with the $\mathrm{V} / \mathrm{S}$ ratio. In other words, $\mathrm{LAP}$, known as a CVDrelated index, was positively correlated with the $\mathrm{V} / \mathrm{S}$ ratio after adjusting for associated variables.

The $\mathrm{V} / \mathrm{S}$ ratio may be predicted to be high even if a patient does not undergo CT given high LAP. Moreover, the results further support previous findings indicating that LAP is a valuable index of $\mathrm{CVD} .{ }^{9,10} \mathrm{CT}$ is an extremely useful test for measuring V/S ratio; it is the most accurate method for measuring abdominal visceral fat because it categorizes and measures visceral and subcutaneous fat. ${ }^{14}$ A previous study showed that $\mathrm{V} / \mathrm{S}$ ratio evaluated by $\mathrm{CT}$ is an independent predictor of mortality and occurrence of cardiac events. ${ }^{15} \mathrm{~V} / \mathrm{S}$ ratio was independently associated with both large and small vessel lesions in apparently healthy subjects in another previous study. ${ }^{16}$ LAP can surpass the BMI in the prediction of CVD risk as an index describing lipid excess accumulation calculated according to the fasting TG level and WC, and there is a positive association between LAP and long-term CVD incidence in CVDfree Caucasian adults. ${ }^{17}$

LAP is largely related to the development and severity of non-al- coholic fatty liver disease (NAFLD) and has a high diagnostic accuracy for identifying patients with NAFLD in the general population. ${ }^{18} \mathrm{LAP}$ has a strong and reliable diagnostic accuracy in the detection of metabolic syndrome in adults without diabetes. ${ }^{19}$ Several previous studies on LAP support the findings of this study that $\mathrm{LAP}$ is associated with $\mathrm{V} / \mathrm{S}$ ratio. That is, $\mathrm{V} / \mathrm{S}$ ratio increases as LAP increases, showing a positive correlation. However, the TG/ $\mathrm{HDL}-\mathrm{C}$ ratio was negatively correlated with the $\mathrm{V} / \mathrm{S}$ ratio. In the study that explored the clinical utility of lipid ratios in the identification of subjects with metabolic syndrome, the TG/HDL-C ratio was used to discriminate between apparently healthy subjects with and without metabolic syndrome. ${ }^{11}$ Other research groups have also proposed that the TG/HDL-C ratio is a potential, simple tool to identify patients at increased risk for insulin resistance and CVD. ${ }^{20-22}$ The TG/HDL-C ratio used to identify individuals at risk may vary across ethnicity and race; TG/HDL-C ratio was an unreliable insulin resistance risk marker in South Asian individuals. ${ }^{23}$ The results are similar to those of our study. As a result of the relationship between $\mathrm{V} / \mathrm{S}$ ratio and CVD risk after adjusting for the general characteristics, the $\mathrm{V} / \mathrm{S}$ ratio was higher in individuals with $\mathrm{WC}>90 \mathrm{~cm}$ than that in individuals with $\mathrm{WC}<90 \mathrm{~cm}$. Some results revealed that $\mathrm{WC}$ is a better indicator of visceral fat and CVD risk compared with BMI and waist to hip ratio. The results of this study showed the same result. ${ }^{2426} \mathrm{~A}$ previous study showed that the $\mathrm{V} / \mathrm{S}$ ratio assessed by ultrasonography is significantly associated with glucose metabolism in patients at high risk of developing type 2 diabetes mellitus. ${ }^{27}$ Several other studies have shown that visceral fat and $\mathrm{V} / \mathrm{S}$ ratio are related to the development of diabetes and $\mathrm{CVD},{ }^{28-31}$ but our study showed that the incidence of diabetes and hypertension was not associated with the $\mathrm{V} / \mathrm{S}$ ratio. As mentioned earlier, there are many studies indicating that LAP is associated with CVD. In this study, the association between LAP and CVD risk factors was not found to be related to other factors except WC and visceral fat mass. The lipid ratios were related to the development of metabolic syndrome and insulin resistance in several studies, ${ }^{11,12}$ but our study did not show any relationship between the lipid ratio and $\mathrm{V} / \mathrm{S}$ ratio. So far, there have been many studies on LAP and chronic metabolic disease and CVD, but there have been no studies on the relationship between LAP and V/S ratio. Moreover, an index such as LAP can have different results based on eth- 
nicity, and this study is valuable because it analyzes the relationship between LAP and V/S ratio and cardiovascular risk factors in domestic adults.

However, this study has some limitations. It was conducted at a single center and all variables that could affect the outcome were not controlled. Therefore, in order to accurately assess the correlation between the LAP and V/S ratio, a multi-institution, largescale, prospective study that complements the previously mentioned points is needed.

This study evaluated LAP among the CVD-related indexes and the relationship between $\mathrm{LAP}$ and $\mathrm{V} / \mathrm{S}$ ratio and cardiovascular risk factor in the domestic population for the first time. The results showed a positive correlation between LAP and V/S ratio. This result can be used to predict the risk of visceral obesity of the visceral fat tissue in patients if LAP is examined, even in those who do not undergo CT. It also supports the importance of LAP as a cardiovascular index, as previous studies have shown. Furthermore, the results can be used as a basis for establishing programs for the management of chronic metabolic disease and CVD.

\section{CONFLICTS OF INTEREST}

The authors declare no conflict of interest.

\section{ACKNOWLEDGMENTS}

This study was supported by a Wonkwang University grant.

\section{AUTHOR CONTRIBUTIONS}

Study concept and design: ALH; acquisition of data: ALH; analysis and interpretation of data: ALH; drafting of the manuscript: SHK; critical revision of the manuscript: SHK; statistical analysis: SHK; administrative, technical, or material support: ALH; and study supervision: ALH.

\section{REFERENCES}

1. Ortega FB, Lavie CJ, Blair SN. Obesity and cardiovascular disease. Circ Res 2016;118:1752-70.
2. Choi B, Steiss D, Garcia-Rivas J, Kojaku S, Schnall P, Dobson $\mathrm{M}$, et al. Comparison of body mass index with waist circumference and skinfold-based percent body fat in firefighters: adiposity classification and associations with cardiovascular disease risk factors. Int Arch Occup Environ Health 2016;89: 435-48.

3. Kawada T, Andou T, Fukumitsu M. Waist circumference, visceral abdominal fat thickness and three components of metabolic syndrome. Diabetes Metab Syndr 2016;10:4-6.

4. Nagaretani H, Nakamura T, Funahashi T, Kotani K, Miyanaga M, Tokunaga K, et al. Visceral fat is a major contributor for multiple risk factor clustering in Japanese men with impaired glucose tolerance. Diabetes Care 2001;24:2127-33.

5. Roriz AK, Passos LC, de Oliveira CC, Eickemberg M, Moreira Pde A, Sampaio LR. Evaluation of the accuracy of anthropometric clinical indicators of visceral fat in adults and elderly. PLoS One 2014;9:e103499.

6. Kim S, Cho B, Lee H, Choi K, Hwang SS, Kim D, et al. Distribution of abdominal visceral and subcutaneous adipose tissue and metabolic syndrome in a Korean population. Diabetes Care 2011;34:504-6.

7. Kaess BM, Pedley A, Massaro JM, Murabito J, Hoffmann U, Fox CS. The ratio of visceral to subcutaneous fat, a metric of body fat distribution, is a unique correlate of cardiometabolic risk. Diabetologia 2012;55:2622-30.

8. Amato MC, Giordano C, Galia M, Criscimanna A, Vitabile S, Midiri M, et al. Visceral Adiposity Index: a reliable indicator of visceral fat function associated with cardiometabolic risk. Diabetes Care 2010;33:920-2.

9. Xia C, Li R, Zhang S, Gong L, Ren W, Wang Z, et al. Lipid accumulation product is a powerful index for recognizing insulin resistance in non-diabetic individuals. Eur J Clin Nutr 2012;66:1035-8.

10. Bozorgmanesh M, Hadaegh F, Azizi F. Predictive performances of lipid accumulation product vs. adiposity measures for cardiovascular diseases and all-cause mortality, 8.6-year follow-up: Tehran lipid and glucose study. Lipids Health Dis 2010;9:100.

11. Gasevic D, Frohlich J, Mancini GJ, Lear SA. Clinical usefulness of lipid ratios to identify men and women with metabolic syndrome: a cross-sectional study. Lipids Health Dis 2014;13:159. 
12. Kawamoto R, Tabara Y, Kohara K, Miki T, Kusunoki T, Takayama S, et al. Relationships between lipid profiles and metabolic syndrome, insulin resistance and serum high molecular adiponectin in Japanese community-dwelling adults. Lipids Health Dis $2011 ; 10: 79$.

13. Taskinen MR, Barter PJ, Ehnholm C, Sullivan DR, Mann K, Simes J, et al. Ability of traditional lipid ratios and apolipoprotein ratios to predict cardiovascular risk in people with type 2 diabetes. Diabetologia 2010;53:1846-55.

14. Tokunaga K, Matsuzawa Y, Ishikawa K, Tarui S. A novel technique for the determination of body fat by computed tomography. Int J Obes 1983;7:437-45.

15. Ladeiras-Lopes R, Sampaio F, Bettencourt N, Fontes-Carvalho R, Ferreira N, Leite-Moreira A, et al. The ratio between visceral and subcutaneous abdominal fat assessed by computed tomography is an independent predictor of mortality and cardiac events. Rev Esp Cardiol (Engl Ed) 2017;70:331-7.

16. Higuchi S, Kabeya Y, Kato K. Visceral-to-subcutaneous fat ratio is independently related to small and large cerebrovascular lesions even in healthy subjects. Atherosclerosis 2017;259:41-5. 17. Kyrou I, Panagiotakos DB, Kouli GM, Georgousopoulou E, Chrysohoou C, Tsigos C, et al. Lipid accumulation product in relation to 10-year cardiovascular disease incidence in Caucasian adults: the ATTICA study. Atherosclerosis 2018;279:10-6.

18. Dai H, Wang W, Chen R, Chen Z, Lu Y, Yuan H. Lipid accumulation product is a powerful tool to predict non-alcoholic fatty liver disease in Chinese adults. Nutr Metab (Lond) 2017; $14: 49$.

19. Taverna MJ, Martínez-Larrad MT, Frechtel GD, Serrano-Ríos M. Lipid accumulation product: a powerful marker of metabolic syndrome in healthy population. Eur J Endocrinol 2011; 164:559-67.

20. Stein E, Kushner H, Gidding S, Falkner B. Plasma lipid concentrations in nondiabetic African American adults: associations with insulin resistance and the metabolic syndrome. Metabolism 2007;56:954-60.

21. Karelis AD, Pasternyk SM, Messier L, St-Pierre DH, Lavoie JM, Garrel D, et al. Relationship between insulin sensitivity and the triglyceride-HDL-C ratio in overweight and obese postmenopausal women: a MONET study. Appl Physiol Nutr
Metab 2007;32:1089-96.

22. McLaughlin T, Reaven G, Abbasi F, Lamendola C, Saad M, Waters D, et al. Is there a simple way to identify insulin-resistant individuals at increased risk of cardiovascular disease? Am J Cardiol 2005;96:399-404.

23. Gasevic D, Frohlich J, Mancini GB, Lear SA. The association between triglyceride to high-density-lipoprotein cholesterol ratio and insulin resistance in a multiethnic primary prevention cohort. Metabolism 2012;61:583-9.

24. Pinho CP, Diniz AD, Arruda IK, Leite AP, Petribu MM, Rodrigues IG. Waist circumference measurement sites and their association with visceral and subcutaneous fat and cardiometabolic abnormalities. Arch Endocrinol Metab 2018;62:416-23. 25. Pouliot MC, Després JP, Lemieux S, Moorjani S, Bouchard C, Tremblay A, et al. Waist circumference and abdominal sagittal diameter: best simple anthropometric indexes of abdominal visceral adipose tissue accumulation and related cardiovascular risk in men and women. Am J Cardiol 1994;73:460-8.

26. Rankinen T, Kim SY, Pérusse L, Després JP, Bouchard C. The prediction of abdominal visceral fat level from body composition and anthropometry: ROC analysis. Int J Obes Relat Metab Disord 1999;23:801-9.

27. Philipsen A, Jørgensen ME, Vistisen D, Sandbaek A, Almdal TP, Christiansen JS, et al. Associations between ultrasound measures of abdominal fat distribution and indices of glucose metabolism in a population at high risk of type 2 diabetes: the ADDITION-PRO study. PLoS One 2015;10:e0123062.

28. Jørgensen ME, Borch-Johnsen K, Stolk R, Bjerregaard P. Fat distribution and glucose intolerance among Greenland Inuit. Diabetes Care 2013;36:2988-94.

29. Fox CS, Massaro JM, Hoffmann U, Pou KM, Maurovich-Horvat $\mathrm{P}$, Liu CY, et al. Abdominal visceral and subcutaneous adipose tissue compartments: association with metabolic risk factors in the Framingham Heart Study. Circulation 2007;116: 39-48.

30. Wander PL, Boyko EJ, Leonetti DL, McNeely MJ, Kahn SE, Fujimoto WY. Change in visceral adiposity independently predicts a greater risk of developing type 2 diabetes over 10 years in Japanese Americans. Diabetes Care 2013;36:289-93.

31. Kanhai DA, Kappelle LJ, van der Graaf Y, Uiterwaal CS, Visseren 
FL; SMART Study Group. The risk of general and abdominal adiposity in the occurrence of new vascular events and mortal- ity in patients with various manifestations of vascular disease. Int J Obes (Lond) 2012;36:695-702. 